\title{
Farmers' preferences for automatic lameness-detection systems in dairy cattle
}

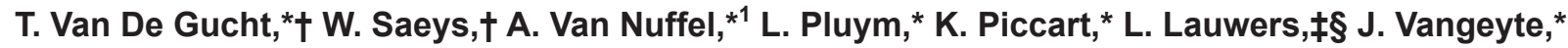 \\ and S. Van Weyenberg* \\ *Technology and Food Sciences Unit, Institute for Agricultural and Fisheries Research (ILVO), Burgemeester van Gansberghelaan 115, \\ 9820 Merelbeke, Belgium \\ †Mechatronics, Biostatistics and Sensors, Department of Biosystems, Katholieke Universiteit Leuven, Kasteelpark Arenberg 30 Box 2456 , \\ 3001 Leuven, Belgium \\ ¥Social Sciences Unit, Institute for Agricultural and Fisheries Research (ILVO), Burgemeester van Gansberghelaan 115, 9820 Merelbeke, \\ Belgium \\ §Department of Agricultural Economics, Faculty of Bio-Engineering, Ghent University, Coupure Links 653, 9000 Gent, Belgium
}

\section{ABSTRACT}

As lameness is a major health problem in dairy herds, a lot of attention goes to the development of automated lameness-detection systems. Few systems have made it to the market, as most are currently still in development. To get these systems ready for practice, developers need to define which system characteristics are important for the farmers as end users. In this study, farmers' preferences for the different characteristics of proposed lameness-detection systems were investigated. In addition, the influence of sociodemographic and farm characteristics on farmers' preferences was assessed. The third aim was to find out if preferences change after the farmer receives extra information on lameness and its consequences. Therefore, a discrete choice experiment was designed with 3 alternative lamenessdetection systems: a system attached to the cow, a walkover system, and a camera system. Each system was defined by 4 characteristics: the percentage missed lame cows, the percentage false alarms, the system cost, and the ability to indicate which leg is lame. The choice experiment was embedded in an online survey. After answering general questions and choosing their preferred option in 4 choice sets, extra information on lameness was provided. Consecutively, farmers were shown a second block of 4 choice sets. Results from 135 responses showed that farmers' preferences were influenced by the 4 system characteristics. The importance a farmer attaches to lameness, the interval between calving and first insemination, and the presence of an estrus-detection system contributed significantly to the value a farmer attaches to lameness-detection systems. Farmers who already use an estrus detection

Received November 6, 2016.

Accepted March 30, 2017.

${ }^{1}$ Corresponding author: annelies.vannuffel@ilvo.vlaanderen.be system were more willing to use automatic detection systems instead of visual lameness detection. Similarly, farmers who achieve shorter intervals between calving and first insemination and farmers who find lameness highly important had a higher tendency to choose for automatic lameness detection. A sensor attached to the cow was preferred, followed by a walkover system and a camera system. In general, visual lameness detection was preferred over automatic detection systems, but this preference changed after informing farmers about the consequences of lameness. To conclude, the system cost and performance were important features, but dairy farmers should be sensitized on the consequences of lameness and its effect on farm profitability.

Key words: farmer preference, technology adoption, discrete choice, automated lameness detection

\section{INTRODUCTION}

Adequate health and welfare monitoring are becoming an important challenge in modern dairy farming (Algers et al., 2009; de Boyer des Roches et al., 2014). Therefore, new sensor technologies to monitor animal health are being developed (Rutten et al., 2013). As lameness is one of the most important health problems, automatic lameness-detection systems are being developed to improve cow health, lowering financial losses and improving animal welfare (Bruijnis et al., 2010; Solano et al., 2015; Van Nuffel et al., 2015b).

The adoption of automatic lameness-detection systems may depend on various factors. In particular, experiences of early adopters, farmer's perception of the lameness problem, and the estimated return on investment may influence the adoption in practice. First, reports of early adopters on their experiences will affect the purchasing behavior of other farmers. Positive experiences may induce a bandwagon effect (Baerenklau, 2005), encouraging other farmers to invest as well. How- 
ever, if the early adopters are dissatisfied, their reports can make other farmers reluctant to purchase such systems, leading to poor adoption caused by a reverse bandwagon effect. Farmer involvement in research and development may help to avoid this by designing systems that meet farmers' expectations (Sanders, 2002; van der Weerdt and de Boer, 2016). Thus far, farmers seem to not yet be involved in the development process of automatic lameness-detection systems.

Second, farmers' perceptions about lameness and its effect on farm profitability may impede the adoption of new technology. Although farmers indicate having enough knowledge (Leach et al., 2010), they are often not aware of the true lameness prevalence in their herd. Wells et al. (1993), Whay et al. (2002), and Espejo et al. (2006) concluded that the prevalence estimated by farmers was 2.5, 4, and 3.1 times lower than the estimation by experts, respectively. The consequences of lameness are also underestimated, implying that farmers are typically not aware of the effect of lameness on farm profitability (Leach et al., 2010). Lack of awareness about lameness, its causes, possible ways to prevent or treat it, and the effectiveness of actions taken, is likely to limit the intentions of farmers to reduce lameness on their farm (Leach et al., 2010; Bruijnis et al., 2013). For example, Alawneh et al. (2012) stated that the interval between detection of the lameness case and treatment was more than $3 \mathrm{wk}$ for more than $40 \%$ of the severely lame cows, indicating that treatment is often delayed. Bruijnis et al. (2013) found that $25 \%$ of the respondents in their study did not believe that cows could suffer pain, although animal welfare was valued as important. These perceptions could falsely lead to the conclusion that new technology is not useful, and hence impede an investment. Main et al. (2012) showed that monitoring and supporting farmers can encourage them to change their lameness management. Thus, farmers might change their attitude about automatic detection systems when they are well informed.

Third, farmers' willingness to adopt new technology also depends on the economic effects of the investment on farm profitability. Borchers and Bewley (2015) concluded that the return on investment, the total investment, and the system performance are important features when considering technology adoption. Therefore, manufacturers should find out how much a farmer wants to pay for a detection system with certain features to design systems that are both affordable and profitable for the farmer.

The goals of our study were, therefore, to (1) investigate which system characteristics of automatic lameness-detection systems are important to farmers, (2) find out how sociodemographic and farm characteristics influence farmers' preferences for lameness detection technology, and (3) find out how farmers' preferences change after receiving extra information about lameness.

\section{MATERIALS AND METHODS}

\section{Experimental Design}

General Approach. A discrete choice experiment was used to investigate which lameness-detection system characteristics determine farmers' preferences. Discrete choice experiments are part of a method to elucidate stated preferences frequently used in agriculture to examine consumer choice behavior in hypothetical situations (Hensher et al., 2005; Lips and Gazzarin, 2008; Louviere et al., 2010). Stated preference approaches can be used for new developments not yet introduced to the market (Meenakshi et al., 2012), which is the case for automatic lameness-detection systems. A disadvantage, however, is that the results are potentially biased, as potential end users could make choices without considering personal constraints (Hensher et al., 2005; Lagerkvist et al., 2006). Therefore, the hypothetical scenarios used in the experiment have to be as realistic as possible (Hensher et al., 2005).

The following potentially important characteristics were put forward: percentage missed lame cows, percentage false alarms, costs per cow per year, and indication of the lame leg. After giving the farmer extra information on the prevalence and cost of lameness, the same experiment was repeated immediately to explore the effect of this extra information on stated preferences.

Respondents were asked to choose between 3 alternative lameness detection systems: a sensor attached to the cow, a walkover system, and a camera system. A fourth option (opt out) was provided to allow respondents to choose human visual inspection as the preferred system to detect lame cows (Table 1). Each option represented a different type of lameness detection with different levels (values) for the system characteristics. An example of such a choice set is illustrated in Table 1 .

The system characteristics were chosen based on our experience, conversations with farmers and discussions during seminars for farmers. The associated levels (value of the characteristic) were based on values reported in recent literature and actual prices of devices, such as accelerometers, already used in practice for estrus detection (Table 2; Bicalho et al., 2007; Van Hertem et al., 2014; Van Nuffel et al., 2015a).

The choice sets were designed using Ngene (ChoiceMetrics, Sydney, Australia) to obtain the smallest possible orthogonal design, to keep the minimum number of respondents needed for the analysis as low as pos- 
Table 1. Example of a choice set as presented to the farmer; only one option or the opt out option could be chosen

\begin{tabular}{|c|c|c|c|c|}
\hline & Option 1 & Option 2 & Option 3 & Option 4 \\
\hline Percentage false alarms & 0 & 5 & 15 & \\
\hline Cost/cow per year $(€)$ & 15 & 35 & 75 & \\
\hline Indication lame leg & Yes & No & Yes & \\
\hline
\end{tabular}

sible (Hensher et al., 2005). In total, 32 choice sets were made.

Choice Experiment. Showing the respondent all 32 choice sets would require an extensive amount of time to complete the survey. This could trigger respondents to end the survey prematurely, leaving some choice sets unanswered. To avoid this, the Ngene software allocated the 32 choice sets to 8 blocks of each 4 choice sets. Each respondent was randomly shown only 1 of these 8 blocks. The effect of providing extra information about lameness was investigated to find out whether choices were influenced after learning more about the consequences of lameness. Therefore, extra information was provided right after finishing the first block of 4 choice sets. Consecutively, a second block of 4 choice sets was shown to the farmer. It should be noted that the second block of 4 choice sets was always different from the first to avoid any farmer copying the same answers from the first block without considering the content. In addition, farmers were not allowed to look back at previous choice sets.

The extra information shown to the farmers was, "Lameness is a top 3 health problem (Enting et al., 1997; Juarez et al., 2003), 5 to $50 \%$ of the cows become lame per year in practice (Rutherford et al., 2009; Pérez-Cabal and Alenda, 2014; Somers and O'Grady, 2015) and farmers only recognize one-fourth to one-half of the lame cows (Whay et al., 2002; Rutherford et al., 2009; Fabian et al., 2014)." Additionally, it was stated that treatment is often performed too late (Alawneh et al., 2012), and that several implications of lameness involve financial losses, such as reduced milk production from 4 mo before up to 5 mo after lameness detection, with an average milk loss of $357 \mathrm{~kg}$ (Green et al., 2002;

Table 2. Lameness detection system characteristics and their levels used in the discrete choice experiment

\begin{tabular}{ll}
\hline System characteristic & Possible level \\
\hline Percentage missed lame cows & $0,10,20,30$ \\
Percentage false alarms & $0,5,10,15$ \\
Costs/cow per year $(€)$ & $15,35,55,75$ \\
Indication lame leg & Yes, no \\
\hline
\end{tabular}

Archer et al., 2010); more missed estruses because of less active cows (Morris et al., 2011); and higher treatment costs and labor (Bruijnis et al., 2010). It was also mentioned that lameness costs around $€ 70 /$ cow on the farm per year compared with $€ 78 /$ cow per year for mastitis (Huijps et al., 2008). This value was based on $€ 53 /$ cow in the herd per year, as calculated by Bruijnis et al. (2010), and the current market situation after the abolishment of the European milk quota in 2015, for which lameness costs were later estimated at $€ 81 /$ cow per year by Hogeveen (2015).

General Questions About Farm and Management. General questions were asked at the start of the survey to get an idea of the farm situation and the farm management. These questions were translated into sociodemographic and farm characteristics used in the analysis of the discrete choice experiment. For some questions, an open answer was allowed, others had predefined answers to choose from (Table 3).

Data Collection. Data were collected based on an online survey using LimeSurvey (Schmitz, 2015). The link needed for participation was sent to Flemish dairy farmers by email, incorporated in newsletters and mentioned on the website of the cow sensor knowledge platform (Koesensor, 2014). An agricultural trade union (Boerenbond, Leuven, Belgium) and the Flemish milk control center (MCC Vlaanderen, Lier, Belgium) sent the email to their members. As such, only farmers who have access to internet and email were targeted. Dairy farms in Flanders are family businesses, and hence privately owned; often these farms combine dairying activities with crop cultivation or other livestock rearing. Thus, the target group consisted of all types of dairy farms, regardless of the level of automation or type of management. Moreover, published information on management practices and level of automation on Flemish dairy farms is scarce. The survey started on June 3, 2014, and was active for a period of 2 mo.

\section{Data Analysis}

Theoretical Background for Analysis of Discrete Choice Experiments. The analysis of discrete 
choice experiments is based on random utility theory, as first proposed by Thurstone (1927) and adapted later (McFadden, 1986; McFadden and Train, 2000; Louviere et al., 2010). This theory assumes that a person attaches a certain utility to each choice option he can choose from. These utilities cannot be observed by the researcher, but can be estimated by summarizing a systematic (explainable) and a random (unexplainable) component. The systematic component exists of attributes (i.e., system characteristics) that indicate differences between choice options, and other variables, known as sociodemographic characteristics (SDC), that indicate differences between individuals. The random component consists of unknown aspects that influence the decision process as well. The utility of a specific option $\left(U_{i j}\right)$ is given by the formula

$$
U_{i j}=V_{i j}+\varepsilon_{i j}
$$

where $U_{i j}$ is the utility of individual $j$ for choice option $i$ [with possible options: a sensor attached to the cow $(i$ $=1)$, walkover system $(i=2)$, camera system $(i=3)$, and opt out $(i=4)], V_{i j}$ is the systematic component of individual $j$ for option $i$, and $\varepsilon_{i j}$ is the random component of individual $j$ for choice option $i$. The systematic component, $V_{i j}$, can be written more specifically when incorporating the attributes of the options $(X)$ and the SDC of the farmers:

$$
\begin{aligned}
V_{i j} & =\beta_{0 i j}+\beta_{1 i j} X_{1 i j}+\beta_{2 i j} X_{2 i j}+\ldots+\beta_{k i j} X_{k i j}+\beta_{1 j i} S_{1 j}[2] \\
& +\beta_{2 j i} S_{2 j}+\ldots+\beta_{n j i} S_{n j},
\end{aligned}
$$

where $\beta_{k i j}$ is the weight of the $k$ th attribute for option $i$ for individual $j, X_{k i j}$ is the $k$ th attribute for option $i$ for individual $j, \beta_{n j i}$ is the weight of the $n$th SDC for option $i$ for individual $j$, and $S_{n j}$ is the measurement of the associated $n$th SDC for individual $j$.

As the utilities of different options in a choice set are not the same, the respondent chooses the option that has the highest utility in his opinion. The analyst, however, can only estimate the probability of an option to be chosen from the obtained information. The probability of a respondent choosing option $i$ is the probability that the utility of option $i$ is larger than that of option $i i$ after evaluating all options in the choice set

\begin{tabular}{|c|c|c|}
\hline Characteristic & Description & Answer options \\
\hline Age & Age category of the respondent & $<30,31-40,41-55,>55$ yr \\
\hline Production & Average milk production ( $\mathrm{kg}$ of milk/cow per year) & Open \\
\hline Milking system & Milking system used & $\begin{array}{l}\text { Milking robot, carousel, herringbone, side-by-side, } \\
\text { tandem, other }\end{array}$ \\
\hline Estrus detection & Use of an estrus-detection system & Yes, no \\
\hline Detection system & If estrus-detection system present, which one & $\begin{array}{l}\text { Pedometer, activity meter neck, sensor in ear, } \\
\text { progesterone in milk }\end{array}$ \\
\hline Reason no system & If no estrus-detection system present, why not & $\begin{array}{l}\text { Too expensive, not user friendly, misses cows in } \\
\text { estrus, too many false alarms, rather do it myself, } \\
\text { other }\end{array}$ \\
\hline Calving interval & $\begin{array}{l}\text { What is the average calving interval on your farm } \\
\text { in days }\end{array}$ & $<380,380-400,400-420,>420$, I don’t know \\
\hline Endometritis & Percentage cows with endometritis & $<10 \%, 10-20 \%, 20-30 \%,>30 \%$, I don't know \\
\hline Footbaths & Use of footbaths & $\begin{array}{l}\text { Never, few times a year, monthly, biweekly, weekly, } \\
\text { backpack sprayer }\end{array}$ \\
\hline Hoof trimming & Frequency of hoof trimming & $\begin{array}{l}\text { Never, once a year routinely, twice a year routinely, } \\
\text { more than twice a year, the whole herd when } \\
\text { needed for a part of the herd, part of the herd } \\
\text { when needed for the whole herd, other }\end{array}$ \\
\hline Prevalence lameness & Lameness prevalence ( $\%$ cows per year) & Open \\
\hline Lameness importance & $\begin{array}{l}\text { Importance of lameness for the productivity and } \\
\text { the wellbeing of the cows }\end{array}$ & Scale of 1 to 10 (not important-very important) \\
\hline Lameness cost & Cost of a lame cow & $\begin{array}{l}\text { Estimate cost, I really don't know how much a } \\
\text { lame cow costs }\end{array}$ \\
\hline
\end{tabular}
[sensor attached to the cow $(i i=1)$, walkover system

Table 3. Farm characteristics, their description and possible answers 
$(i i=2)$, camera system $(i i=3)$, and opt out $(i i=4)]$. This probability can be written as

$\operatorname{Prob}_{i}=\operatorname{Prob}\left[\left(V_{i}+\varepsilon_{i}\right) \geq\left(V_{i i}+\varepsilon_{i i}\right) \forall i i \in i i=1, \ldots, J: i \neq i i\right]$.

From formula [3], the probability an individual chooses option $i$ over the other available options $i i$ can be derived,

$$
\operatorname{Prob}_{i}=\frac{\exp \left(V_{i}\right)}{\sum_{i i=1}^{4} \exp \left(V_{i i}\right)} \forall i i \in i i=1, \ldots, 4 \text { and } i \neq i i,
$$

which can then be used later on to perform simulations to compare options with different attribute levels.

Modeling the Response Data. Farmers' choices were analyzed using Nlogit (Econometric Software Inc., Plainview, NY) using a multinomial logit model. In the first step of the analysis, the base model that describes the utility of each option was defined using the 4 attributes from the choice experiment with a multinomial logit model. For each option $i$, the utility was described by

$$
\begin{aligned}
U_{i: 1, \text { cow-attached }} & =\beta_{01}+\beta_{1} \times \text { missedLame }+\beta_{2} \times \text { falseAlarms } \\
& +\beta_{3} \times \text { cost }+\beta_{4} \times \text { indicateLeg } ; \\
U_{i: 2, \text { walk-over }}= & \beta_{02}+\beta_{1} \times \text { missedLame }+\beta_{2} \times \text { falseAlarms } \\
& +\beta_{3} \times \text { cost }+\beta_{4} \times \text { indicateLeg } ; \\
U_{i: 3, \text { camera }}= & \beta_{03}+\beta_{1} \times \text { missedLame }+\beta_{2} \times \text { falseAlarms } \\
& +\beta_{3} \times \text { cost }+\beta_{4} \times \text { indicateLeg; }
\end{aligned}
$$

and

$$
U_{i: 4, \text { opt-out }}=0,
$$

where $\beta$ is the attribute constant, missedLame is the percentage of missed lame cows, falseAlarms is the percentage false alarms, cost is the cost of the system, and indicateLeg is the possibility of the system to indicate which leg is lame.

In a second step, SDC and management characteristics (referred to as SDC) were defined and tested in a univariable way by adding them separately to the base model (Table 4). Therefore, some SDC were transformed by effect coding to facilitate the analysis and interpretation, whereas others were not retained in the analysis due to a lack of specific information or too little variation in the designated answers (Table 4). The SDC contributed significantly to the model when the $P$-value of the coefficient was smaller than 0.15. After determining which SDC were significant at the univariable level, a multivariable model was built using these SDC. The final model was then obtained by reducing the multivariable model to the SDC that were found to be also significant on the multivariable level $(P<0.05)$. A characteristic before/after extra information was added to the analysis, representing whether a choice set was shown to the farmer before or after the extra information to find out whether this information significantly contributed to the utility model. This way, comparing farmer preference across farmers before and after receiving extra information was possible.

Goodness of model fit was analyzed by calculating the pseudo-coefficient of determination (Hensher et al., 2005):

$$
\text { Pseudo } R^{2}=1-\frac{L L_{\text {Estimated_model }}}{L L_{\text {Null_model }}},
$$

Table 4. Sociodemographic and management characteristics retained in the analysis with their respective grouping levels (values in parentheses indicate the effect coding values assigned to the respective group level)

\begin{tabular}{ll}
\hline Sociodemographic and management characteristic & Grouping levels and coding reference \\
\hline Farmer age & $>55 ; \leq 55 \mathrm{yr}(-1,1)$ \\
Importance of lameness & $\leq$ level $7 ;>$ level $7(-1,1)$ \\
Interval calving to first insemination (dummy 1$)$ & $\leq 100 \mathrm{~d}(1,0) ;>100 \mathrm{~d}(-1,-1) ;$ I don't know $(0,1)$ \\
Interval calving to first insemination (dummy 2) & Yes; No $(1,-1)$ \\
Estrus-detection system present & Yes; No $(1,-1)$ \\
Pasture allowed & $\%$ Lame cows \\
Percentage lameness & Yes; No $(1,-1)$ \\
Has idea of cost of lameness & Yes; No $(1,-1)$ \\
Use of footbaths & Milking robot $(1,0) ;$ conventional (tandem, herringbone, carousel, side by side) \\
Type of milking system (dummy 1) & $(-1,-1) ;$ stanchion barn $(0,1)$ \\
Type of milking system (dummy 2) & Number of cows \\
Number of cows on the farm & $\leq 8,500 \mathrm{~kg} ;>8,500 \mathrm{~kg}(-1,1)$ \\
Kilograms of milk production per year & Before; after $(-1,1)$ \\
Before/after extra information &
\end{tabular}


where $L L_{\text {Estimated_model }}$ is the log-likelihood of the final model and $L L_{\text {Null_model }}$ is the log-likelihood of the null model including attribute constants $(\beta 0)$ only. According to Hensher et al. (2005), a pseudo-coefficient of determination of 0.3 represents a decent model fit for a discrete choice experiment.

Model Interpretation. Estimated model coefficients should be interpreted with care, as their value depends on the range of attribute levels used in the choice experiment (Hensher et al., 2005). Hence, coefficient estimates should not be compared between attributes or SDC included in the model. The utility assigned to an alternative with specific attribute levels is more informative. However, the utility derived from the choice model as described above is only meaningful when compared with that of another alternative in the choice experiment. In our study, visual lameness detection performed by the farmer (opt-out option) was used as a reference. The utility of all options is therefore related to the utility of the opt-out option, which was set to zero (formula [5]). Utilities higher than zero indicate that the respective alternative is found more useful than the opt-out option and is thus preferred by the respondents. When an attribute level is increased by 1 unit, the utility assigned to the alternative increases with the value of the attribute's coefficient estimate in case of a positive estimate and vice versa, provided that all other attribute levels are kept constant. The units used in this study were 1 percentage point for the percentage of missed lame cows and percentage false alarms, $€ 1 /$ cow per year for the system cost, and present or absent as a representation of the ability to indicate which leg is lame.

\section{RESULTS}

\section{Survey Results}

Farm Situation and Background. In total, 135 dairy farmers completed the survey. Most farmers (37\%) originated from West Flanders, whereas 25\% from East Flanders, 23\% from Antwerp, 13\% from Limburg, and $2 \%$ from Flemish Brabant. The age distribution of the respondents was $22,27,43$, and $8 \%$ for the age classes younger than 30 , between 30 and 40 , between 40 and 55 , and older than 55, respectively. Sixty-seven percent of the farmers allowed their cows to go on pasture. The average herd size was 94 cows and ranged from 15 to 560 cows, with a median herd size of 75 cows. The average milk production on the farm varied from 6,100 to $12,000 \mathrm{~kg} /$ cow per year, with an average of $8,879 \mathrm{~kg}$.

Farm Automation. All main milking system types were represented in the responses: $33 \%$ of the farms had a herringbone system, $21 \%$ a side-by-side system, $20 \%$ a milking robot, $15 \%$ a tandem system, $6 \%$ a stanchion barn, and $4 \%$ a carousel. On 2 out of 5 farms, an estrusdetection system was present.

Farmer Lameness Perception. Seventy-eight percent of the farmers assigned lameness an importance of level 8 or more on a scale from 1 to 10 . Lameness prevalence was estimated lower than $10 \%$ by $40 \%$ of the farmers, and between 10 and $20 \%$ by another $36 \%$ of the farmers. Thirty-four percent of the farmers indicated to never use a footbath on their farm, whereas $21 \%$ applied footbaths a few times a year, $5 \%$ used them once a month, $30 \%$ biweekly, $7 \%$ once a week, and $3 \%$ used a backpack sprayer instead of a footbath. Farmers had varying ideas of the cost of a lame cow; however, only $37 \%$ of the farmers made an estimation of the cost, as the rest indicated they had no idea of the cost of a lame cow. Of those farmers who did make an estimation, $8 \%$ estimated the cost of a lame cow less than €50, 17\% estimated between €50 and €100, $13 \%$ between $€ 100$ and $€ 150,10 \%$ between $€ 150$ and $€ 200$, $21 \%$ between $€ 200$ and $€ 250,10 \%$ between $€ 250$ and $€ 300,6 \%$ between $€ 350$ and $€ 400,10 \%$ between $€ 450$ and $€ 500$, and $4 \%$ estimated the cost higher than $€ 500$ per lame cow.

\section{Choice Experiment}

Modeling Results. In Table 5, the coefficient values, standard error, and significance of each estimated coefficient in the base model, univariable models, and multivariable model are summarized. The final multivariable model was

$$
\begin{aligned}
U_{i} & =\beta_{0 i}+\beta_{1} \times \text { missedLame }+\beta_{2} \times \text { falseAlarms } \\
& +\beta_{3} \times \text { cost }+\beta_{4} \times \text { indicateLeg } \\
& +\beta_{\text {IMPLAMENESS } \times \text { impLameness }} \\
& +\beta_{\text {CALFINSEMD } 1 \times \text { calfInsemd } 1} \\
& +\beta_{\text {CALFINSEMD } 2 \times \text { calfInsemd } 2+\beta \text { ESTDET } \times \text { estDet } 1} \\
& +\beta_{\text {BEFOREAFTER }} \times \text { beforeafter },
\end{aligned}
$$

where impLameness is the importance the farmer attached to lameness, calfInsemd 1 and calfInsemd 2 are the dummy variables for the interval between calving and first insemination, estDet is the presence of an estrus-detection system, and beforeafter is whether the choice set was shown before or after extra information about lameness, each with its corresponding coefficient $(\beta)$. The pseudo-coefficient of determination of the final model was 0.19 , which is equal to a coefficient of determination of about 0.45 , but less than the aimed 
Table 5. Analysis results of the base model, univariable models with sociodemographic characteristics and the final multivariable model ${ }^{1}$

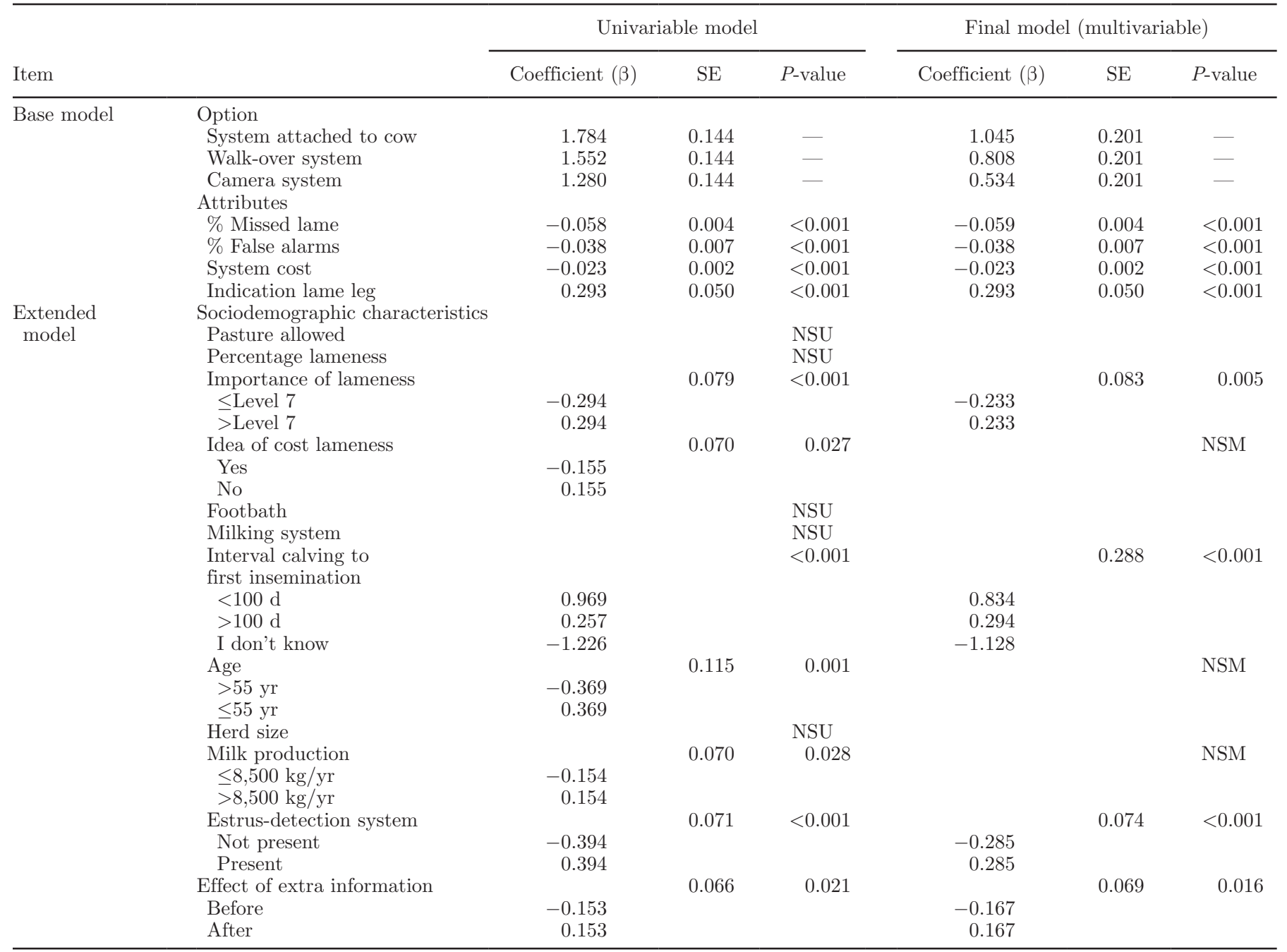

${ }^{1} \mathrm{NSU}=$ not significant in the univariate model; NSM = variable significant in the univariable model, but not significant in the multivariate model.

for pseudo-coefficient of determination of 0.3 (Hensher et al., 2005).

In the final model, all system attribute coefficients were highly significant. If the percentage missed lame cows would be decreased by 1 percentage point, the utility of the respective alternative would increase by 0.059 (Table 5). Similarly, lowering the percentage false alarms by 1 percentage point would result in a utility increase of 0.038 . Decreasing system cost with $€ 1$ would increase utility by 0.023 , and a system capable of indicating which leg is lame would have a utility 0.293 higher compared with that of a similar system not capable of indicating which leg is lame.

Concerning the SDC, the importance of lameness, the presence of an estrus-detection system, farmer's age, and the interval from calving to first insemination were significant $(P<0.001)$ in the univariable models. Milk production, whether the farmer had an idea on the cost of lameness, and the extra information about lameness were also univariable significant $(P<0.15$; Table 5$)$. In the final model, only the importance of lameness, the interval from calving to first insemination, the presence of an estrus-detection system, and the extra information were retained, as they significantly contributed to the model $(P<0.05)$.

If the farmer attached level 8 or more to the importance of lameness, the alternative's utility increased by 0.233 , whereas levels of 7 or lower decreased utility by 0.233 (Table 5); hence, the utility assigned to a specific alternative differed by 0.466 between both groups. Similarly, the presence of an estrus-detection system increased utility by 0.285 , whereas absence resulted in a 
decrease of 0.285 (Table 5). Farmers who did not know the interval between calving and first insemination on their farm decreased utility by 1.128 , whereas farmers who report an interval of more than $100 \mathrm{~d}$ increased utility by 0.294 . Farmers who reported an interval of under $100 \mathrm{~d}$ assigned utility 0.834 higher, resulting in a total utility difference of 1.962 between this group and those who did not know the interval on their farm. Providing extra information about the prevalence and costs of lameness increased utility by 0.334 in total.

Average Lameness-Detection System Utilities. The mean utility for each option before and after providing extra information about lameness is shown in Figure 1. Results were separated for the different levels of the significant SDC in the multivariable model (Table 5). In Figure 1A, the general utility comparison is presented. Compared with the opt-out situation, in which the farmer visually detects lameness himself without the help of a detection system, each automatic detection system scored negative. A sensor attached to the cow had the highest (least negative) utility, followed by a walkover system and a camera system. All utilities were negative on average, indicating that visual detection was preferred over any of the automated systems. After providing extra information, all utilities became less negative.

Farmers who had an estrus-detection system assigned higher utility values to all options involving a sensor compared with farmers without an estrus-detection system (Figure 1B). After extra information, the average utilities became positive for a sensor attached to the cow and a walkover system, indicating that those respective systems were preferred over visual detection by farmers who have estrus-detection systems on their farm. Farmers who did not know the average interval length on their farm assigned the lowest utility to the lameness-detection systems (Figure 1C). Farms with a calving interval larger than $100 \mathrm{~d}$ assigned a higher utility, but lower than farms with an interval smaller than 100 d. Again, after providing information about lameness, the utilities increased for all systems. Farmers who attached more importance to lameness assigned higher utility values to the detection systems compared with farmers who found lameness less important, but after the extra information both groups assigned higher utility values.

\section{DISCUSSION}

\section{General Remarks on Survey Results}

The percentage of respondents per region corresponded fairly well with the percentage of Flemish dairy farmers situated in each Flemish region in 2015, which was $37,30,17,9$, and $8 \%$ for Western Flanders, East Flanders, Antwerp, Limburg, and Flemish Brabant, respectively (Belgian Federal Government, 2016). The median herd size was similar to the Flemish average herd size of 77 cows (CRV, 2016), but the average milk production per year was slightly higher than the Flemish average of $8,515 \mathrm{~kg}$ (CRV, 2016). The distribution of used milking systems corresponded fairly well with that of Flanders, as $39 \%$ of the Flemish farmers use a herringbone system, $7 \%$ a side-by-side system, $11 \%$ a milking robot, $16 \%$ a tandem system, $23 \%$ a stanchion barn, $3 \%$ a carousel, and $1 \%$ another type of milking system (S. Van Weyenberg, MILControl, Merelbeke, Belgium, personal communication). The percentage of farms equipped with an estrus-detection system was slightly lower than the $26 \%$ found in an earlier study of 208 farms (Santon, 2013).

In our study, no response rate could be calculated, as it was unknown how many farmers had been reached after spreading the link to the survey through the different communication channels. The absolute number of respondents (135) was comparable to the studies of Mollenhorst et al. (2012) and Huijps et al. (2009), with 139 and 136 respondents, respectively. Our results showed that farms with a milking robot were overrepresented and farms with a stanchion barn underrepresented. The gathered data seemed to come from farms with more technology compared with the Flemish average. Hence, preferences of farmers with low production levels and little technology may be under-represented in these data, indicating that some selection bias was likely present. However, one could question if such selection bias is problematic for the interpretation of the results. Farms with low production levels and little technology are likely to be small farms, whereas the farmer is often close to reaching retirement age without having a successor to take over the farm. Moreover, as almost 50\% of the new milking installations in Belgium are milking robots (Fedagrim, 2017), the average technology level of farms that will stay in business is increasing.

Only $37 \%$ of the farmers in our sample gave an estimate for the cost of a lame cow when asked for it, which may seem low; however, this result accords with the study of Leach et al. (2010), where only $30 \%$ of the farmers gave an estimate. This suggests that most of the farmers in our study are insufficiently aware of the cost associated with lameness in their herds. This could be because they may not really know the consequences of lameness well, which was previously also stated by Leach et al. (2010), or because they are simply not interested in it and thus have no idea of the cost and various financial consequences. This indicates the im- 


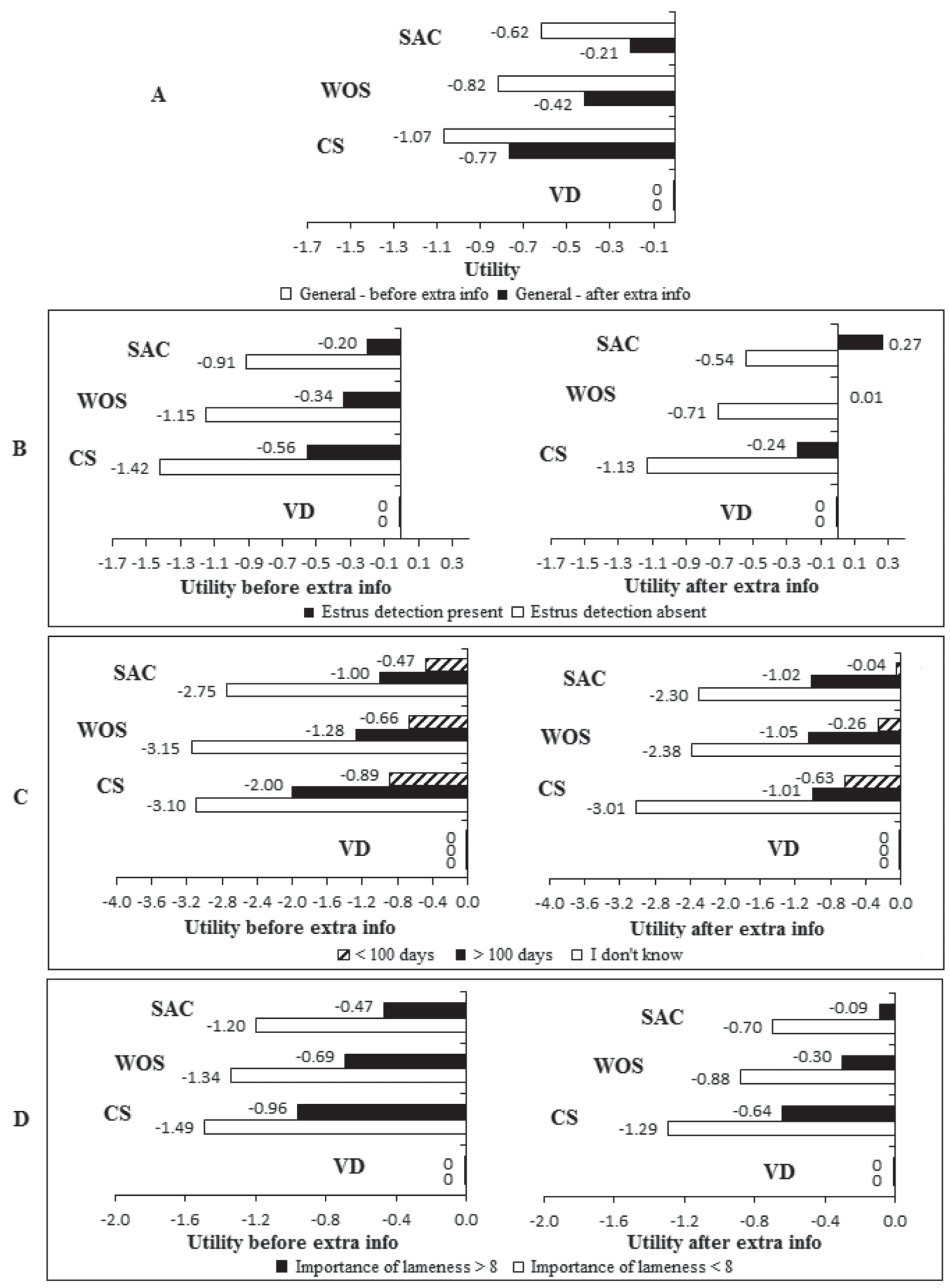

Figure 1. Comparison of the utility of each option: system attached to the cow (SAC), walkover system (WOS), camera system (CS), and visual detection (VD) before and after providing extra information about the consequences of lameness. (A) General comparison; (B) separated for farms with an estrus-detection system present and farms without an estrus detection system; (C) separated for farms with $<100 \mathrm{~d}$ from calving to conception, >100 d from calving to conception, and farmers who don't know the interval from calving to conception on their farm; and (D) separated for farmers who find lameness very important (level $\geq 8$ ) and farmers who find it less important (level <8). 
portance of the third aim of our study, regarding the effect of providing extra information about lameness on farmers' preferences.

\section{Analysis of the Discrete Choice Experiment}

Importance of Automatic Lameness Detection System Characteristics. The first goal of our study was to investigate which characteristics of automatic lameness-detection systems are important to farmers. All 4 characteristics (\% missed lame cows, \% false alarms, system cost, and indication of the lame leg) contributed significantly to the model and were important to the farmer. As Bewley (2010) stated, the perceived economic return is one of the main influencing factors of technology adoption. The economic return partially depends on the system cost, which explains its importance in the results. Similarly to the study of Mollenhorst et al. (2012) on estrus-detection systems, sensitivity (\% missed lame cows) and specificity (\% false alarms) were important features as well. The ability to indicate which leg is lame was also considered valuable.

Our results showed that the sensor systems were not equally preferred by farmers. The system attached to the cow was preferred most, followed by the walkover system and the camera system. It is possible that the cow-attached sensor was favored because it reminded farmers of the existing pedometer and accelerometer systems used in estrus detection. Another possible explanation could be that farmers had their own barn layout in mind and were less convinced that the walkover and camera systems could be installed in their barn. However, no explanation could be found for the higher preference for the walkover sensor compared with the camera system.

Importance of Sociodemographic and Farm Characteristics. The second aim of this study was to find out how sociodemographic characteristics influence farmers' preferences for automatic lameness-detection systems. Several SDC indeed influenced farmers' preferences. Farmers who already use an estrus-detection system assigned positive values to the sensor attached to the cow and the walkover system after extra information. These farmers are used to working with such technology. Hence, they could have a better insight in the possible value of the detection systems. This is in agreement with the findings of Khanal et al. (2010), who stated that adopters of a particular technology are also adopters of other technologies. Another explanation could be that these farmers thought that the lameness detection would just be an addition to their estrus-detection system, and hence would not incur drastic changes on the farm or farm management. These farmers might also simply have a progressive attitude, and are thus more interested in technology compared with their colleagues who do not have estrus-detection systems.

The interval between calving and first insemination also had an effect on the utility values of the sensor systems. The shorter the interval was, the higher the utility of lameness-detection systems became. This could indicate that farmers with good fertility results in their herd are more focused on health problems in general, and attach more value to detection systems. Farmers who attached high importance to lameness also gave higher utility values to the automatic detection systems. This suggests that they are more interested in technology-based solutions or value the proposed sensors more highly compared with those who do not see lameness as a very important problem and might underestimate the problem as a whole. To conclude, farmers have a preference for different automatic lameness-detection systems based on their current farm management and situation, and also on a tradeoff between several system characteristics, including performance indicators and financial implications.

Importance of Informing Farmers About Lameness Consequences. The third goal of our study was to investigate whether farmers change their preferences for automatic lameness-detection systems after learning more about the consequences of lameness. This was indeed found to be true, as the variable describing whether a choice set was evaluated before or after showing the extra information contributed significantly to the final utility model. On average, the utility values of the detection systems were larger after extra information was provided. In other words, sensors with similar values for percent of missed lame cows, percent of false alarms, system cost, and lame leg indication were, on average, valued higher than before the information was provided. This indicates that farmers valued the sensor systems differently after learning more about the economic impact of lameness. A possible explanation could be that farmers did actually learn from this information, which might have influenced their opinion about the values of characteristics of automatic lameness-detection systems.

However, after receiving extra information, utilities remained negative on average, except for farmers who already had an estrus-detection system. Hence, on average, visual lameness detection was still preferred. Leach et al. (2010) and Bell et al. (2009) indicated that farmers' underestimation of the lameness problem and its consequences might be the main reason why they are reluctant to implement new intervention strategies to reduce lameness on their farm. This could explain why the utility values of the sensor systems were nega- 
tive and visual detection was preferred over the other options, in general, before the information was shown. In a similar way, farmers could be cautious to step away from their current lameness management based on visual detection. Moreover, as the economic value of lameness-detection sensors is still unknown, farmers may find it difficult to balance their perceived financial loss against the system cost, especially because they underestimate these losses (Leach et al., 2010). As a result, the potential value of a lameness-detection sensor might be underestimated. Nevertheless, the extra information seemed to have triggered a reaction from the farmer, as preferences for automatic lameness-detection systems were generally higher after reading the information. It can thus be concluded that informing farmers and increasing awareness about lameness can trigger farmers to change their preferences regarding automatic lameness-detection systems.

\section{CONCLUSIONS}

Our results indicated that the number of missed lame cows and false alarms, the system cost, and the ability to indicate which leg is lame are important features of automatic lameness-detection systems. On average, farmers did not prefer automatic systems over visual lameness detection. However, farmers' preferences changed after receiving more information about the consequences of lameness, leading to more interest in the automated detection systems. Furthermore, a farmer's preference was based on a tradeoff between the type of system and system characteristics, including performance indicators and the system cost, and sociodemographic characteristics, such as farm management and other farm characteristics. Our study yields the hypothesis that dairy farmers might not be sufficiently aware of the consequences of lameness. Lack of knowledge implies a challenge for technology developers and manufacturers. Also, a niche market of farmers who already have a degree of technology on their farm could be targeted as potential early adopters of the new technology.

\section{ACKNOWLEDGMENTS}

This work was supported by the ICT-agri Eranet Smart Integrated Livestock Farming (SILF) project, the University of Leuven (KU Leuven), Leuven, Belgium, the Institute for Agriculture and Fisheries Research (ILVO), Merelbeke, Belgium, and the Flemish Agency for Innovation by Science and Technology (IWT), Brussels, Belgium, as part of the "koesensor" LA-traject 110770 . We gratefully thank the farmers who responded to our survey.

\section{REFERENCES}

Alawneh, J. I., R. A. Laven, and M. A. Stevenson. 2012. Interval between detection of lameness by locomotion scoring and treatment for lameness: A survival analysis. Vet. J. 193:622-625.

Algers, B., H. J. Blokhuis, A. Botner, D. M. Broom, P. Costa, M. Domingo, M. Greiner, J. Hartung, F. Koenen, M. G. Christine, R. Mohan, D. Morton, A. Osterhaus, D. U. Pfeiffer, R. Roberts, M. Sanaa, M. Salman, J. M. Sharp, P. Vannier, and M. Wierup. 2009. Scientific opinion on the overall effects of farming systems on dairy cow welfare and disease. EFSA J. 1143:1-38.

Archer, S. C., M. J. Green, and J. N. Huxley. 2010. Association between milk yield and serial locomotion score assessments in UK dairy cows. J. Dairy Sci. 93:4045-4053.

Baerenklau, K. A. 2005. Toward an understanding of technology adoption: Risk, learning, and neighborhood effects. Land Econ. 81:1-19.

Belgian Federal Government. 2016. Agricultural data 2015. Accessed May 31, 2016. http://statbel.fgov.be/nl/modules/publications/ statistiques/economie/downloads/agriculture_-_chiffres_d_ agricole_de_2015.jsp.

Bell, N. J., M. J. Bell, T. G. Knowles, H. R. Whay, D. J. Main, and A. J. F. Webster. 2009. The development, implementation and testing of a lameness control programme based on HACCP principles and designed for heifers on dairy farms. Vet. J. 180:178-188.

Bewley, J. 2010. Precision dairy farming: Advanced analysis solutions for future profitability. Pages 1-8 in Proceedings of the first North American Conference on Precision Dairy Management, March 2-5, 2010, Toronto, ON, Canada. Progressive Dairy Operators, Guelph, ON, Canada.

Bicalho, R. C., S. H. Cheong, G. Cramer, and C. L. Guard. 2007. Association between a visual and an automated locomotion score in lactating holstein cows. J. Dairy Sci. 90:3294-3300.

Borchers, M. R., and J. M. Bewley. 2015. An assessment of producer precision dairy farming technology use, prepurchase considerations, and usefulness. J. Dairy Sci. 98:4198-4205.

Bruijnis, M., H. Hogeveen, C. Garforth, and E. Stassen. 2013. Dairy farmers' attitudes and intentions towards improving dairy cow foot health. Livest. Sci. 155:103-113.

Bruijnis, M. R. N., H. Hogeveen, and E. N. Stassen. 2010. Assessing economic consequences of foot disorders in dairy cattle using a dynamic stochastic simulation model. J. Dairy Sci. 93:2419-2432.

CRV. 2016. Jaarstatistieken. Accessed May 31, 2016. https://www. crv4all.be/downloads/prestaties/jaarstatistieken/.

de Boyer des Roches, A., I. Veissier, M. Coignard, N. Bareille, R Guatteo, J. Capdeville, E. Gilot-Fromont, and L. Mounier. 2014. The major welfare problems of dairy cows in French commercial farms: an epidemiological approach. Anim. Welf. 23:467-478.

Enting, H., D. Kooij, A. A. Dijkhuizen, R. B. M. Huirne, and E. N. Noordhuizen-Stassen. 1997. Economic losses due to clinical lameness in dairy cattle. Livest. Prod. Sci. 49:259-267.

Espejo, L. A., M. I. Endres, and J. A. Salfer. 2006. Prevalence of lameness in high-producing Holstein cows housed in freestall barns in Minnesota. J. Dairy Sci. 89:3052-3058.

Fabian, J., R. A. Laven, and H. R. Whay. 2014. The prevalence of lameness on New Zealand dairy farms: A comparison of farmer estimate and locomotion scoring. Vet. J. 201:31-38.

Fedagrim. 2017. Economisch Dossier 2016/2017. Op zoek naar stabiliteit. De uitrustingsector doorgelicht. Page 73. Fedagrim, Belgian Federation of Agricultural Equipment Importers, Brussels, Belgium.

Green, L. E., V. J. Hedges, Y. H. Schukken, R. W. Blowey, and A. J. Packington. 2002. The impact of clinical lameness on the milk yield of dairy cows. J. Dairy Sci. 85:2250-2256.

Hensher, D. A., J. M. Rose, and W. H. Greene. 2005. Applied Choice Analysis: A Primer. Vol. 3. Cambridge University Press, Cambridge, UK.

Hogeveen, H. 2015. Economie van klauwgenzondheid. [Presentation]. Seminar: Studiedag kreupelheid: Wat loopt er mank? November 20, 2015. Merelbeke, Belgium.

Huijps, K., H. Hogeveen, T. J. G. M. Lam, and R. B. M. Huirne. 2009. Preferences of cost factors for mastitis management among Dutch 
dairy farmers using adaptive conjoint analysis. Prev. Vet. Med. 92:351-359.

Huijps, K., T. J. Lam, and H. Hogeveen. 2008. Costs of mastitis: Facts and perception. J. Dairy Res. 75:113-120.

Juarez, S. T., P. H. Robinson, E. J. DePeters, and E. O. Price. 2003. Impact of lameness on behavior and productivity of lactating Holstein cows. Appl. Anim. Behav. Sci. 83:1-14.

Khanal, A. R., J. Gillespie, and J. MacDonald. 2010. Adoption of technology, management practices, and production systems in US milk production. J. Dairy Sci. 93:6012-6022.

Koesensor. 2014. Kenniscentrum sensoren in de melkveehouderijKnowledge platform dairy cattle sensors. Accessed May 4, 2017. http://www.koesensor.be.

Lagerkvist, C. J., F. Carlsson, and D. Viske. 2006. Swedish consumer preferences for animal welfare and biotech: A choice experiment. J. Agrobiotechnology Manag. Econ. 9:51-58.

Leach, K. A., H. R. Whay, C. M. Maggs, Z. E. Barker, E. S. Paul, A. K. Bell, and D. C. J. Main. 2010. Working towards a reduction in cattle lameness: 1 . Understanding barriers to lameness control on dairy farms. Res. Vet. Sci. 89:311-317.

Lips, M., and C. Gazzarin. 2008. What are the preferences of dairy farmers regarding their work? A discrete choice experiment in the eastern part of Switzerland. Pages 1-6 in Proc. 12th Congress of the European Association of Agricultural Economists - EAAE 2008, August 26-29. Ghent, Belgium.

Louviere, J. J., T. N. Flynn, and R. T. Carson. 2010. Discrete choice experiments are not conjoint analysis. J. Choice Model. 3:57-72.

Main, D. C. J., K. A. Leach, Z. E. Barker, A. K. Sedgwick, C. M. Maggs, N. J. Bell, and H. R. Whay. 2012. Evaluating an intervention to reduce lameness in dairy cattle. J. Dairy Sci. 95:2946-2954.

McFadden, D. 1986. The choice theory approach to market research. Mark. Sci. 5:275-297.

McFadden, D., and K. Train. 2000. Mixed MNL models for discrete response. J. Appl. Econ. 15:447-470.

Meenakshi, J. V., A. Banerji, V. Manyong, K. Tomlins, N. Mittal, and P. Hamukwala. 2012. Using a discrete choice experiment to elicit the demand for a nutritious food: Willingness-to-pay for orange maize in rural Zambia. J. Health Econ. 31:62-71.

Mollenhorst, H., L. J. Rijkaart, and H. Hogeveen. 2012. Mastitis alert preferences of farmers milking with automatic milking systems. J. Dairy Sci. 95:2523-2530.

Morris, M. J., K. Kaneko, S. L. Walker, D. N. Jones, J. E. Routly, R. F. Smith, and H. Dobson. 2011. Influence of lameness on follicular growth, ovulation, reproductive hormone concentrations and estrus behavior in dairy cows. Theriogenology 76:658-668.

Pérez-Cabal, M. A., and R. Alenda. 2014. Clinical lameness and risk factors in a Spanish Holstein population. Livest. Sci. 164:168-174.

Rutherford, K. M. D., F. M. Langford, M. C. Jack, L. Sherwood, A. B. Lawrence, and M. J. Haskell. 2009. Lameness prevalence and risk factors in organic and non-organic dairy herds in the United Kingdom. Vet. J. 180:95-105.

Rutten, C. J., A. G. J. Velthuis, W. Steeneveld, and H. Hogeveen. 2013. Invited review: Sensors to support health management on dairy farms. J. Dairy Sci. 96:1928-1952.

Sanders, E. B. N. 2002. From user-centered to participatory design approaches. Pages 1-8 in Design and the Social Sciences: Making Connections. CRC Press, Boca Raton, FL.

Santon, S. 2013. Een melkveestal vol sensoren: Welke worden gekocht, welke worden gebruikt? BSc thesis. Departement Biotechniek, KAHO Sint-Lieven, Sint-Niklaas, Belgium.

Schmitz, C. 2015. Cow sensor knowledge platform. LimeSurvey: An Open Source Survey Tool. LimeSurvey Project Team, Hamburg, Germany. Accessed Feb. 22, 2016. http://www.koesensor.be

Solano, L., H. W. Barkema, E. A. Pajor, S. Mason, S. J. LeBlanc, J. C. Zaffino Heyerhoff, C. G. R. Nash, D. B. Haley, E. Vasseur, and D. Pellerin. 2015. Prevalence of lameness and associated risk factors in Canadian Holstein-Friesian cows housed in freestall barns. J. Dairy Sci. 98:6978-6991.

Somers, J., and L. O'Grady. 2015. Foot lesions in lame cows on 10 dairy farms in Ireland. Ir. Vet. J. 68:10.

Thurstone, L. L. 1927. A law of comparative judgment. Psychol. Rev. $34: 273$.

van der Weerdt, C., and J. de Boer. 2016. Focusing on behaviour to ensure adoption of big data information services in precision lifestock farming. Pages 721-729 in Proc. 7th European Conference on Precision Livestock Farming, 15-18 September, Milan, Italy.

Van Hertem, T., S. Viazzi, M. Steensels, E. Maltz, A. Antler, V. Alchanatis, A. A. Schlageter-Tello, K. Lokhorst, E. C. B. Romanini, and C. Bahr. 2014. Automatic lameness detection based on consecutive 3D-video recordings. Biosyst. Eng. 119:108-116.

Van Nuffel, A., W. Saeys, B. Sonck, J. Vangeyte, K. C. Mertens, B. De Ketelaere, and S. Van Weyenberg. 2015a. Variables of gait inconsistency outperform basic gait variables in detecting mildly lame cows. Livest. Sci. 177:125-131.

Van Nuffel, A., I. Zwertvaegher, S. Van Weyenberg, M. Pastell, V. M. Thorup, C. Bahr, B. Sonck, and W. Saeys. 2015b. Lameness detection in dairy cows: Part 2. Use of sensors to automatically register changes in locomotion or behavior. Animals (Basel) 5:861-885

Wells, S. J., A. M. Trent, W. E. Marsh, and R. A. Robinson. 1993. Prevalence and severity of lameness in lactating dairy cows in a sample of Minnesota and Wisconsin herds. J. Am. Vet. Med. Assoc. 202:78-82.

Whay, H. R., D. C. J. Main, L. E. Green, and A. J. F. Webster. 2002. Farmer perception of lameness prevalence. Pages 355-358 in 12th International Symposium on Lameness in Ruminants. 9-13 January 2002, Florida. 